\title{
Life Satisfaction and Quality of Life Enjoyment among Retired People Aged 65 or Older
}

\author{
Florence Mei Fung Wong \\ School of Nursing, Tung Wah College, Hong Kong, China \\ Email: florencewong@twc.edu.hk
}

How to cite this paper: Wong, F.M.F. (2019) Life Satisfaction and Quality of Life Enjoyment among Retired People Aged 65 or Older. Open Journal of Social Sciences, 7, 119-127.

https://doi.org/10.4236/jss.2019.75009

Received: April 2, 2019

Accepted: May 14, 2019

Published: May 17, 2019

\begin{abstract}
Ageing is a global concern. Today, we emphasize healthy ageing with life satisfaction and better quality of life. The advanced technology in healthcare services and medical treatment has led to greater longevity. Although older people reach retirement age at 65 , they continue to work for their career. Retirement can be a financial impact as the working older people cannot continue to earn money for their living. They need to rely on support from their family and the government. Retirement is also the factor to make dramatically changes in roles and responsibilities, authority, social network, and self-value. This study aimed 1) to examine the level of life satisfaction and quality of life enjoyment and 2) to identify relationships between demographic characteristics and life satisfaction and quality of life enjoyment among older people aged 65 or older. The study results are significant to show the important areas to improve life satisfaction and quality of life enjoyment among older people aged 65 or older. Social relationship, particularly, support from family is the most important element to enhance life satisfaction and quality of life enjoyment in retired people.
\end{abstract}

\section{Keywords}

Life Satisfaction, Quality of Life Enjoyment, Older People, Retirement

\section{Introduction}

Ageing is a global issue. The World Health Organization (WHO) estimated a dramatic increase in ageing population aged 60 from $12 \%$ in 2015 to $22 \%$ in 2050 [1]. Many countries have adopted aged 65 as the retirement age. Due to an increase in the number of retired people and a decline in the number of birth rate, ageing together with retirement becomes a huge social and economic concern [2]. The latest population projection showed that there will be about one 
third of population aged 65 or older in Hong Kong by 2041. The report also showed one in every three people who reached 65 in 2066 [3]. Moreover, ageing population may also trigger health concerns due to comorbidities and health needs for related healthcare/rehabilitative services. As a result, ageing embraces various challenges in social, economic, and health issues. Maintaining life satisfaction and quality of life is crucial to prolong life and promote health in older people [1].

A research suggested that older people who were active in the labour force with pay or voluntarily reported higher level of life satisfaction probably because they had better social support [4] [5]. Numerous studies showed that being re-employment was greatly associated with better feeling of well-being and better life satisfaction [6] [7] [8]. However, according to the report from the Census and Statistics Department in 2015, the percentage of the older people aged 65 or above in the labour force was decreased from 9.3 in the first quarter to 8.7 in the second quarter [3]. Those people may be forced to retire due to regulations of the organizations. It results in an increased burden of government in various public resources for ageing population on one hand, ageing population may be re-employed for their financial needs, self-esteem, and life satisfaction [4] [9] [10].

Living well in ageing has been the global priority [1]. In Hong Kong, people at aged 65 are said to be retirement. Due to the advanced medical technique and better nutrition, people at retirement ages are still energetic and are still able to actively engage in their career. Retirement can be an impact to economic-social stability in people aged 65 or older. Retirement can make dramatically changes in roles and responsibilities, authority, social network, and self-value. Such changes may negatively affect life satisfaction and quality of life in those older population [8]. Considering healthy ageing and active ageing, the desire of retired people shall be linked to life satisfaction and quality of life enjoyment [6]. This study aimed 1) to examine life satisfaction and quality of life enjoyment and 2) to understand relationships between demographic characteristics and life satisfaction and quality of life enjoyment among older people aged 65 or older.

\section{Methods}

\subsection{Design and Sampling}

A cross-sectional questionnaire survey was conducted using convenience sampling to understand more about the life satisfaction and quality of life in older people aged 65 or older. Patients were recruited when they 1) have been retired at aged 65 or older; 2) Hong Kong residents; 3 ) were able to understand Chinese; and 4) had no cognitive problems.

\subsection{Data Collection}

After the ethical approval was obtained, the in-charge manager of an elderly service centre was met to discuss about the study purpose and procedure of data 
collection so that the operation of the centre would not be affected. All eligible subjects were invited to participate in the study. Once they agreed, they would be asked to sign an informed consent and fill in one set of questionnaires, including the demographic form and the questionnaire related to life satisfaction and quality of life enjoyment via face-to-face interviews. The interview took about 20 minutes.

The Short form of Quality of Life Enjoyment and Satisfaction Questionnaire (Q-LES-Q-SF) a generic tool to measure life satisfaction and quality of life among the older people. There are 16 items of Q-LES-Q-SF with 5-Likert scale ranging from 1 (very poor) to 5 (very good). The items are related to physical health, mood, work, household duties, school/course work, leisure time activities, and social relations.

The last two items are not included in the total score but standalone items. The minimum raw total score of Q-LES-Q-SF is 14 and the maximum raw total score is 70 . When the score is close to 70, it indicates better life satisfaction and quality of life [11]. The reliability and validity of the Q-LES-Q-SF were performed with Cronbach alpha 0.9 and the test-retest reliability 0.93 [12].

\section{Ethical Considerations}

Ethical approval was sought by the School Research Committee of the educational institution. All subjects were assured that they could withdraw from the study without consequences at any time. All information was anonymous for personal confidentiality.

\section{Results}

\subsection{Demographic Characteristics}

A total of 42 subjects were recruited, including 32 males and 10 females. Most of the subjects aged at $80-89(\mathrm{n}=24 ; 57.1 \%)$. Half of the subjects were widowed ( $\mathrm{n}$ $=21)$ and living with spouse only $(n=21 ; 50 \%)$. The financial status of the subjects was comparable, almost evenly distributed. Table 1 shows the details of demographic characteristics of older people aged 65 or above.

\subsection{Q-LES-Q-SF among Older People Aged 65 or above}

Based on the Q-LES-Q-SF results, the range of the raw score was 25 to 69 . The item of social relationships (mean 4.05 SD 1.06) was rated as the most significant aspect; subsequently, the items of family relationships (mean 3.79 SD 1.22), living/housing situation (mean 3.79 SD 1.16), leisure time activities (mean 3.76 SD 1.12), and ability to function in daily life (mean 3.74 SD 1.17) were the significant aspects related to better life satisfaction and quality of life in those older people aged 65 or older. The results also showed that the items of work (mean $2.95 \mathrm{SD}$ 1.31) and sexual drive, interest, and/or performance (mean $2.62 \mathrm{SD}$ 1.13) were the poorest importance in those age population for life satisfaction and quality of life. Regarding overall sense of wellbeing and overall life satisfaction 
Table 1. Demographic characteristics.

\begin{tabular}{|c|c|}
\hline Demographic characteristics & Number (percentage)/N (\%) \\
\hline \multicolumn{2}{|l|}{ Age } \\
\hline 65 - 69 years old & $4(9.5)$ \\
\hline $70-79$ years old & $12(28.6)$ \\
\hline $80-89$ years old & $24(57.1)$ \\
\hline 90 - 99 years old & $1(2.4)$ \\
\hline$\geq 100$ years old & $1(2.4)$ \\
\hline \multicolumn{2}{|l|}{ Gender } \\
\hline Male & $32(76.2)$ \\
\hline Female & $10(23.8)$ \\
\hline \multicolumn{2}{|l|}{ Marital status } \\
\hline Married & $16(38.1)$ \\
\hline Divorced & $5(11.9)$ \\
\hline Widowed & $21(50.0)$ \\
\hline \multicolumn{2}{|l|}{ Education } \\
\hline None & $17(40.5)$ \\
\hline Educated & $35(49.5)$ \\
\hline \multicolumn{2}{|l|}{ Living status } \\
\hline With spouse only & $21(50)$ \\
\hline With family & $10(23.8)$ \\
\hline With friend & $11(26.2)$ \\
\hline \multicolumn{2}{|l|}{ Financial status } \\
\hline Full independence & $15(35.7)$ \\
\hline Partial dependence & $13(31.0)$ \\
\hline Full dependence & $14(33.3)$ \\
\hline
\end{tabular}

and contentment during the past week, the mean scores were higher than 3.6. The Cronbach's alpha was 0.79 indicating a good reliability. Table 2 shows the details of Q-LES-Q-SF among older people aged 65 or above.

\subsection{Relationships of Demographic Characteristics and Q-LES-Q-SF}

The relationships were found between demographic characteristics and the items of the Q-LES-Q-SF. Table 3 shows the relationships of demographic characteristics and Q-LES-Q-SF.

Age was found to have significant negative associations with mood $(\gamma=$ $-0.336, \mathrm{p}=0.029)$, work $(\gamma=-0.440, \mathrm{p}=0.004)$, family relationship $(\gamma=-0.342$, $\mathrm{p}=0.027)$, leisure time activities $(\gamma=-0.355, \mathrm{p}=0.021)$, and medication $(\gamma=$ $-0.418, \mathrm{p}=0.006)$. The most significant negative relationship was found between age and work. 
Table 2. Q-LES-Q-SF among older people aged 65 or above.

\begin{tabular}{ll}
\hline $\begin{array}{l}\text { The Short form of Quality of Life Enjoyment and Satisfaction Questionnaire } \\
\text { (Q-LES-Q-SF) }\end{array}$ & Mean (SD) \\
\hline Physical Health & $3.26(1.25)$ \\
Mood & $3.60(1.17)$ \\
Work & $2.95(1.31)$ \\
Household activities & $3.48(1.15)$ \\
Social relationships & $4.05(1.06)$ \\
Family relationships & $3.79(1.22)$ \\
Leisure time activities & $3.76(1.12)$ \\
Ability to function in daily life & $3.74(1.17)$ \\
Sexual drive, interest and/or performance & $2.62(1.13)$ \\
Economic status & $3.45(1.21)$ \\
Living/Housing situation & $3.79(1.16)$ \\
Ability to get around physically without feeling dizzy or unsteady or falling & $3.40(1.21)$ \\
Your vision in terms of ability to do work or hobbies & $3.19(1.04)$ \\
Overall sense of well being & $3.62(1.17)$ \\
Medication & $3.48(1.23)$ \\
How would you rate your overall life satisfaction and contentment during & $3.69(1.05)$ \\
\hline &
\end{tabular}

The significant positive relationships were found between gender and physical health $(\gamma=0.334, \mathrm{p}=0.031)$, $\operatorname{mood}(\gamma=0.341, \mathrm{p}=0.027)$, work $(\gamma=0.497, \mathrm{p}=$ $0.001)$, household activities $(\gamma=0.355, \mathrm{p}=0.021)$, social relationships $(\gamma=0.349$, $\mathrm{p}=0.024)$, family relationships $(\gamma=0.331, \mathrm{p}=0.032)$. Work was found to have the most positive significant association with gender.

The results showed that only work had significant negative relationship with marital status $(\gamma=-0.293, \mathrm{p}=0.060)$. There was no item of Q-LES-Q-SF associated with living status.

Education was found to have significant positive associations with $\operatorname{mood}(\gamma=$ $0.375, \mathrm{p}=0.014)$, work $(\gamma=0.368, \mathrm{p}=0.016)$, social relationships $(\gamma=0.422, \mathrm{p}=$ 0.005), family relationships ( $\gamma=0.477, \mathrm{p}=0.001)$, leisure time activities $(\gamma=0.387$, $\mathrm{p}=0.011)$, economic status $(\gamma=0.366, \mathrm{p}=0.017)$, and overall life satisfaction and contentment $(\gamma=0.376, \mathrm{p}=0.014)$. Social relationships and family relationship were found to have the most significant positive association with educational level.

Financial status was found to have significant negative association with physical health $(\gamma=-0.320, \mathrm{p}=0.039)$, family relationships $(\gamma=-0.329, \mathrm{p}=0.034)$, leisure time activities $(\gamma=-0.383, \mathrm{p}=0.012)$, economic status $(\gamma=-0.314, \mathrm{p}=$ 0.043 ), and ability to get around physically without feeling dizzy or unsteady or falling $(\gamma=-0.313, \mathrm{p}=0.044)$. 
Table 3. Relationships of demographic characteristics and Q-LES-Q-SF.

\begin{tabular}{|c|c|c|c|c|c|c|c|c|c|c|c|c|}
\hline \multirow{2}{*}{ Q-LES-Q-SF } & \multicolumn{2}{|c|}{ Age } & \multicolumn{2}{|c|}{ Gender } & \multicolumn{2}{|c|}{ Marital status } & \multicolumn{2}{|c|}{ Living status } & \multicolumn{2}{|c|}{ Educational level } & \multicolumn{2}{|c|}{ Financial status } \\
\hline & $\begin{array}{c}\text { Pearson } \\
\text { correlation }\end{array}$ & $\mathrm{p}$ & $\begin{array}{c}\text { Pearson } \\
\text { correlation }\end{array}$ & $\mathrm{p}$ & $\begin{array}{c}\text { Pearson } \\
\text { correlation }\end{array}$ & $\mathrm{p}$ & $\begin{array}{c}\text { Pearson } \\
\text { correlation }\end{array}$ & $\mathrm{p}$ & $\begin{array}{c}\text { Pearson } \\
\text { correlation }\end{array}$ & $\mathrm{p}$ & $\begin{array}{c}\text { Pearson } \\
\text { correlation }\end{array}$ & $\mathrm{p}$ \\
\hline Physical Health & -0.160 & 0.311 & 0.334 & $0.031^{*}$ & -0.089 & 0.574 & 0.083 & 0.601 & 0.121 & 0.445 & -0.320 & $0.039^{*}$ \\
\hline Mood & -0.336 & $0.029^{*}$ & 0.341 & $0.027^{*}$ & -0.110 & 0.488 & 0.023 & 0.883 & 0.375 & $0.014^{*}$ & -0.182 & 0.249 \\
\hline Work & -0.440 & $0.004^{*}$ & 0.497 & $0.001^{* *}$ & -0.293 & $0.060^{*}$ & 0.143 & 0.365 & 0.368 & $0.016^{*}$ & -0.179 & 0.257 \\
\hline Household activities & -0.263 & 0.093 & 0.355 & $0.021^{*}$ & -0.098 & 0.535 & 0.119 & 0.455 & 0.199 & 0.205 & -0.230 & 0.144 \\
\hline Social relationships & -0.237 & 0.132 & 0.349 & $0.024^{*}$ & -0.055 & 0.731 & -0.014 & 0.929 & 0.422 & $0.005^{*}$ & -0.226 & 0.150 \\
\hline Family relationships & -0.342 & $0.027^{*}$ & 0.331 & $0.032^{*}$ & -0.232 & 0.140 & 0.138 & 0.384 & 0.477 & $0.001^{* *}$ & -0.329 & $0.034^{*}$ \\
\hline Leisure time activities & -0.355 & $0.021^{*}$ & 0.120 & 0.449 & -0.042 & 0.703 & 0.220 & 0.161 & 0.387 & $0.011^{*}$ & -0.383 & $0.012^{*}$ \\
\hline $\begin{array}{l}\text { Sexual drive, interest } \\
\text { and/or performance }\end{array}$ & -0.040 & 0.801 & 0.292 & 0.060 & -0.255 & 0.103 & 0.132 & 0.403 & 0.238 & 0.129 & 0.099 & 0.533 \\
\hline Economic status & -0.055 & 0.715 & 0.069 & 0.665 & 0.058 & 0.713 & -0.035 & 0.826 & 0.366 & $0.017^{*}$ & -0.314 & $0.043^{*}$ \\
\hline $\begin{array}{l}\text { Living/Housing } \\
\text { situation }\end{array}$ & 0.089 & 0.577 & 0.056 & 0.726 & 0.024 & 0.880 & 0.071 & 0.656 & -0.040 & 0.801 & -0.142 & 0.369 \\
\hline $\begin{array}{l}\text { Ability to get around } \\
\text { physically without feeling } \\
\text { dizzy or unsteady } \\
\text { or falling }\end{array}$ & -0.255 & 0.103 & 0.185 & 0.242 & -0.193 & 0.221 & 0.262 & 0.094 & 0.245 & 0.119 & -0.313 & $0.044^{*}$ \\
\hline $\begin{array}{l}\text { Your vision in terms of } \\
\text { ability to do work } \\
\text { or hobbies }\end{array}$ & -0.286 & 0.066 & 0.005 & 0.974 & 0.076 & 0.634 & 0.052 & 0.741 & 0.096 & 0.543 & -0.124 & 0.433 \\
\hline Medication & -0.418 & $0.006^{*}$ & 0.286 & 0.066 & -0.197 & 0.212 & 0.227 & 0.148 & 0.195 & 0.216 & -0.262 & 0.093 \\
\hline $\begin{array}{l}\text { How would you rate your } \\
\text { overall life satisfaction } \\
\text { and contentment during } \\
\text { the past week }\end{array}$ & -0.212 & 0.178 & 0.221 & 0.159 & -0.110 & 0.488 & 0.025 & 0.876 & 0.376 & $0.014^{*}$ & -0.152 & 0.337 \\
\hline
\end{tabular}

${ }^{*} \mathrm{p}<0.05 ;{ }^{* *} \mathrm{p}<0.001$.

\section{Discussion}

The results revealed that most of the people aged 65 or above perceived better quality of life and life satisfaction in the aspects of family relationship, joining leisure activities, living and housing situation and enabling to function in daily life. It meant that social network is still important in retirement life. Social support, especially family support, is a good remedy. Most of the retired people in this study were married and living with their families. Much evidence showed that family is the greatest support to maintain psychosocial wellbeing. Once the older person is retired, his/her family will be his/her support to adapt to the transition [4] [13]. During the transition, the older person experiences changes, such as role change, financial change, and social network change [13]. These changes can induce psychological distress leading to severe consequences such as elderly depression and attempting suicide. Other than that, establishing social 
network is another important support. Through joining leisure activities, older retired people can build up their social support system and are able to interact with others [4] [10] [14].

Moreover, the retired people feel more quality of life enjoyment and life satisfaction in the living and housing situation. A good living environment can provide better health condition to improve quality of life and satisfaction of living. The result also showed that the retired people had better quality of life enjoyment and life satisfaction when they found themselves functioning in daily life. That means they are able to be independent and take care of themselves. Independence is another important element of better quality of life. Retired people may have lost their authority and sense of control [13]. Independence indicates ability of self-mastery and control that are important for respect and dignity.

The results also showed that better mood may have higher life satisfaction and quality of life enjoyment. Psychological status can affect the sense of satisfaction [15]. In overall, the people aged 65 or above had better life satisfaction.

People who had less life satisfaction and quality of life enjoyment in "work" and "sexual drive, interest, and/or performance" areas. In this study, most of the subjects aged 70 or older. At these ages, they may not be able to fulfil the work tasks due to physical intolerance [15]. To people who are retired, employment may not be a desire as they are not able to obtain fair benefits. Moreover, sexual interest not be the desire either to those people. Those factors impact life satisfaction and quality of life enjoyment due to low self-esteem [13] [15].

The results also found that people who were male had significant positive relationship with life satisfaction and quality of life enjoyment in various areas particularly in their work. It is understood that men are the major breadwinners especially in Asian countries [13] [16]. Career increases personal value and self-esteem [10] [13]. Those who are younger will have better life satisfaction and quality of life in mood, work, family relationship and leisure time activities. It indicates that those people are still energetic and independent. They want to enjoy their life through social relationship or activities [13] [15]. Those who had higher education had significant positive relationships with various areas of life satisfaction and quality of life enjoyment, including mood, work, social relationship, leisure time activities, economic status, and particularly in their family relationship. A supportive social network is able to enhance the self-value and recognition in those retired people [4] [10]. It is important to note that family support is important to life satisfaction and quality of life enjoyment in retired people [4] [17]. Life satisfaction had been viewed as an attainment of a desired end and fulfilment of essential conditions, particularly in Chinese population [15]. After retirement, those people experience sudden changes including their roles and responsibilities. Support from their families and others can enhance their sense of life satisfaction and quality of life enjoyment because their concerns can be listened and assisted. They can be respected and valued within their social network [4] [10] [14]. 
The limitation of this study was small sample size. The results of factors associated with life satisfaction and quality of life may not be appropriately identified. A cross-sectional design may not provide the results with cause-and-effect. A longitudinal study with a larger sample may be more accurate to understand life satisfaction and quality of life in retired people aged 65 or older and related associated factors.

\section{Conclusion}

Ageing is a global concern. In general, people at age 65 are tired. They will experience a big change in life and in their living. Those changes are the impacts to their life satisfaction and their quality of life is also affected. The sense of life satisfaction is based on the achievement and fulfilment with their roles. In this study, the results showed that retired people may still have life satisfaction and quality of life enjoyment in various areas. Relationships with family and others are the most important factors to improve sense of life satisfaction. Through establishing relationships with others in activities, those retired people can enjoy better life satisfaction and quality of life enjoyment. Although retired people are no longer working, they can still find their values and their enjoyment in life. It is important that a variety of factors, including male gender, younger age, higher educational level, and better financial status, have been identified to be associated with specific areas of life satisfaction and quality of life enjoyment. Social support network, particularly support from family, is the most important factor to enhance life satisfaction and quality of life enjoyment in retired people.

\section{Acknowledgements}

I would thank my capstone students in the Bachelor in Health Sciences (Applied Gerontology) (Honors) for their participation in data collection of this research project.

\section{Conflicts of Interest}

The authors declare no conflicts of interest regarding the publication of this paper.

\section{References}

[1] World Health Organization (WHO) (2015) Aging and health. https://www.who.int/news-room/fact-sheets/detail/ageing-and-health

[2] Civic Service Bureau (2015) Retirement. http://www.csb.gov.hk/english/admin/retirement/183.html

[3] Census and Statistics Department (2013) Retirement Planning and the Financial Situation in Old Age. https://www.statistics.gov.hk/pub/B11302522013XXXXB0100.pdf

[4] Borg, C., Hallberg, I.R. and Blomqvist, K. (2006) "Life Satisfaction among Older People (65+) with Reduced Self-Care Capacity: The Relationship to Social, Health and Financial Aspects. Journal of Clinical Nursing, 15, 607-618. 
https://doi.org/10.1111/j.1365-2702.2006.01375.x

[5] Pinquart, M. and Sörensen, S. (2000) Influences of Socioeconomic Status, Social Network, and Competence on Subjective Well-Being in Later Life: A Meta-Analysis. Psychology and Aging, 15, 187. https://psycnet.apa.org/record/2000-03816-001. https://doi.org/10.1037/0882-7974.15.2.187

[6] Andersson, P. (2008) Happiness and Health: Well-Being among the Self-Employed. Journal of Socio-Economics, 37, 213-236. https://doi.org/10.1016/j.socec.2007.03.003

[7] Blanchard-Fields, F. and Fried, T.L. (1988) Age as a Moderator of the Relation between Three Dimensions of Satisfaction and Sex Role. Sex Roles, 18, 759-768. https://doi.org/10.1007/BF00288059

[8] Frijters, P., Haisken-DeNew, J.P. and Shields, M.A. (2004) Money Does Matter! Evidence from Increasing Real Income and Life Satisfaction in East Germany Following Reunification. American Economic Review, 94, 730-740. https://doi.org/10.1257/0002828041464551

[9] Chan, K.H. and Behling, F. (2003) Senior Employment in Asia: Current Conditions, Challenges and Proposals. Journal of State and Society, 14, 1-54.

[10] Çeçen, A.R. (2008) Sense of Coherence, Family Sense of Coherence and Self-Esteem in Predicting Life Satisfaction among University Students. Journal of Theory and Practice in Education, 4, 19-30.

[11] Endicott, J., Nee, J., Harrison, W. and Blumenthal, R. (1993) Quality of Life Enjoyment and Satisfaction Questionnaire. Psychopharmacological Bulletin, 29, 321-326. https://doi.org/10.1037/t49981-000

[12] Stevanovic, D. (2011) Quality of Life Enjoyment and Satisfaction Questionnaire-Short Form for Quality of Life Assessments in Clinical Practice: A Psychometric Study. Journal of Psychiatric and Mental Health Nursing, 18, 744-750. https://doi.org/10.1111/j.1365-2850.2011.01735.x

[13] Lawal, A.M. and Idemudia, E.S. (2017) Life Satisfaction in Retirement: The Direct Influence of Gender, Self-Esteem, and Health Locus of Control in Southern Parts of Nigeria. Studies on Ethno-Medicine, 11, 302-310. https://doi.org/10.1080/09735070.2017.1351515

[14] Yeung, G.T. and Fung, H.H. (2007) Social Support and Life Satisfaction among Hong Kong Chinese Older Adults: Family First? European Journal of Ageing, 4, 219-227. https://doi.org/10.1007/s10433-007-0065-1

[15] Ruuskanen, J.M. and Ruouppila, I. (1995) Physical Activity and Psychological Well-Being among People Aged 65 to 84 Years. Age and Ageing, 24, 292-296. https://doi.org/10.1093/ageing/24.4.292

[16] Ng, S.T., Tey, N.P. and Asadullah, N.N. (2017) What Matters for Life Satisfaction among the Oldest-Old? Evidence from China. PLOS ONE, 12, e0171799. https://doi.org/10.1371/journal.pone.0171799

[17] Meeks, S. and Murrell, S.A. (2001) Contribution of Education to Health and Life Satisfaction in Older Adults Mediated by Negative Affect. Journal of Aging and Health, 13, 92-119. https://doi.org/10.1177/089826430101300105 